\title{
Acute Intermittent Porphyria: Pathophysiology and Treatment
}

\author{
Ujjaini Khanderia, M.S., Pharm.D. and Arjun Bhattacharya, M.D.
}

\begin{abstract}
Acute intermittent porphyria is caused by an inherent error of porphyrin metabolism characterized by a deficiency of porphobilinogen deaminase and increased activity of delta-aminolevulinic acid synthase, key enzymes necessary for the biosynthesis of heme. During an attack patients may have abdominal pain, vomiting, muscle weakness, constipation and neuropsychiatric symptoms. In the majority of individuals the disease remains clinically latent throughout life. Various drugs and chemicals, hormones and nutritional factors predispose to clinical attacks, probably by inducing hepatic delta-aminolevulinic acid synthase. Avoidance of these substances is important in preventing attacks. Screening of family members to detect genetic carriers permits precautionary measures. Management of attacks includes symptomatic therapy, high carbohydrate intake and intravenous administration of hematin.

(Pharmacotherapy 1984;4:144-150)
\end{abstract}

Fundamental Defect

Diagnosis

Clinical Manifestations

Pathology

Precipitating Factors

Management

Treatment of the Acute Attack

Summary

Acute intermittent porphyria (AIP) is a hereditary disorder characterized by an abnormality in the pathway of heme biosynthesis, resulting in an overproduction of precursors of heme. The genetic defect is inherited as an autosomal dominant trait. Although the exact prevalence is not known, the frequency of clinical disease or acute attacks of porphyria is higher in females than in males. Attacks most commonly occur between the ages of 20 to 50 years and are virtually never seen before puberty.

\footnotetext{
From the College of Pharmacy, University of Michigan, Ann Arbor, Department of Pharmacy, University of Michigan Hospitals, Ann Arbor, and the Department of Surgery, Deaconess Hospital, St. Louis.

Address reprint requests to $\mathrm{Dr}$. Khanderia at the Department of Pharmacy, University of Michigan Hospitals, 1405 E. Ann Street, Ann Arbor, Michigan 48109-0010.
}

\section{Fundamental Defect}

Heme is synthesized primarily in the liver and the bone marrow by a complex pathway that involves a series of enzymatic reactions (Figure 1)..$^{1-3}$ Starting with succinyl CoA and glycine, the first step is the formation of delta-aminolevulinic acid (ALA). This reaction, catalyzed by the mitochondrial enzyme deltaaminolevulinic acid synthase (ALA synthase), is the rate-limiting step in the pathway. Under basal conditions, the activity of hepatic ALA synthase is low. Certain drugs and chemicals, however, can induce enzyme activity to levels 50 to 100 times above the baseline. ${ }^{4-6} A$ increased demand for heme can also induce hepatic ALA synthase. Heme, the end product of the pathway, represses hepatic ALA synthase through a negative feedback effect as shown in Figure 1. The activity of ALA synthase is known to be limiting for overall heme synthesis in the liver. It is not clear if this is also the case in the bone marrow or in most other organs.

Another key enzyme in the pathway is porphobilinugen deaminase (PBG deaminase), which has frequently been referred to as uroporphyrinogen I synthetase. Recent evidence indicates that $P B G$ deaminase does not produce uroporphyrinogen directly, but forms a straight-chain tetrapyrrole, hydroxymethylbilane, which then undergoes cyclization to produce uroporphyrinogen I. $^{7}$ In acute intermittent porphyria, PBG deaminase activity is approximately $50 \%$ of that seen in normal individuals. A deficiency of PBG deaminase activity, even to $50 \%$ of normal, in itself is not sufficient to cause overpro- 


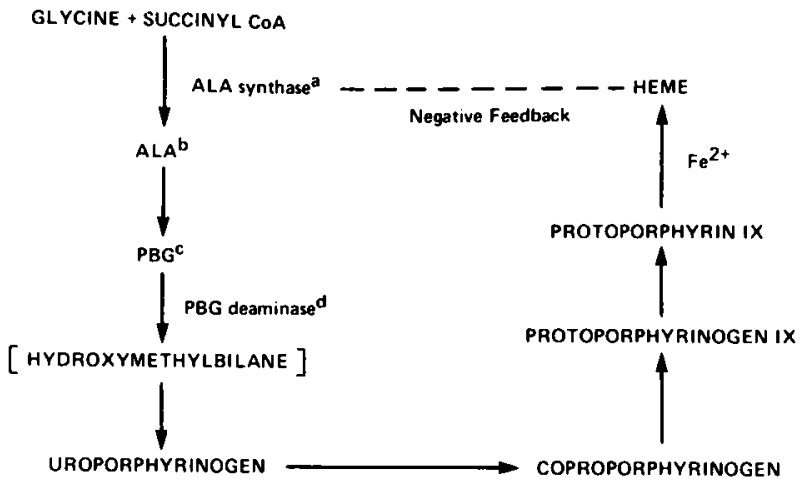

$$
\begin{aligned}
& \text { a. } \delta \text {-aminolevulinic acid synthase } \\
& \text { b. } \delta \text {-aminolevulinic acid } \\
& \text { c. Porphobilinogen } \\
& \text { d. Porphobilinogen deaminase }
\end{aligned}
$$

Figure 1. Heme biosynthetic pathway.

duction or overexcretion of the porphyrin precursors. Also required is an increase in ALA synthase activity, coupled with a loss of ALA and porphobilinogen (PBG) from hepatocytes and perhaps other cells. The disease in the majority (about $90 \%$ ) of AIP remains clinically latent, and patients seldom excrete excessive quantities of porphyrin precursors, even though deficiency of PBG deaminase is present. It is likely that in latent carriers, hepatic ALA synthase activity is normal. Drugs, chemicals and factors that exacerbate AIP appear to act by inducing ALA synthase, the rate-controlling enzyme for hepatic heme synthesis. In AIP, overproduction of ALA and PBG occur in the liver, not in the bone marrow.

\section{Diagnosis}

Evaluation for AIP should include measurement of PBG in urine and PBG deaminase in erythrocytes. The Watson-Schwartz test ${ }^{8}$ is widely used for qualitative determination of PBG in urine. The drawbacks with qualitative tests presently available are low sensitivity and lack of specificity. False positive or negative results may occur for a variety of reasons. Urinary PBG should be determined quantitatively ${ }^{9}$ when AIP is suspected. During an attack, patients excrete excessive quantities of PBG in urine; with clinical improvement, this usually decreases. In the differential diagnosis of acute symptoms that may be due to acute porphyria, it is important to measure urinary porphobilinogen and to demonstrate by qualitative and preferably quantitative methods increases in urinary PBG concentrations.

Porphobilinogen deaminase is most conveniently measured in erythrocytes. ${ }^{10,11}$ Although in AIP the mean enzyme activity is approximately $50 \%$ of normal, a wide range in PBG deaminase activity has been observed, with overlap between normal and disease ranges. ${ }^{1,2,12,13}$ Activity of PBG deaminase in patients with AIP may fall within the normal range, and more often, within an indeterminate range between normal and disease values. ${ }^{13}$ Assay of the deaminase, therefore, totally fails in some cases to diagnose the condition.

Measurement of PBG deaminase in erythrocytes is useful for detecting clinically latent gene carriers in families of patients with known AIP. ${ }^{12}$ Because most persons with clinically latent disease have normal urinary PBG excretion, the enzyme assay is more useful for diagnosis. In cases where PBG deaminase activity falls into a range that is nondiagnostic, repeat assays, quantitative determinations of urinary PBG and family genetic analysis are helpful in diagnosis. ${ }^{12.13}$

\section{Clinical Manifestations}

Acute intermittent porphyria mimics a variety of other disorders and is therefore difficult to diagnose on the basis of signs and symptoms alone. The clinical pattern is quite variable. Although the disease is characterized by exacerbations and remissions, a great many patients remain asymptomatic throughout their lifetime. The most common symptoms include abdominal pain, nausea, vomiting, constipation, back pain, muscle weakness, tachycardia, hypertension and a variety of neuropsychiatric symptoms. ${ }^{1,2,6,14.15}$ Abdominal pain is the principal symptom in approximately $85 \%$ or more of the attacks. Pain may be localized or general, is often colicky and may simulate appendicitis or biliary colic. Pain in the back and extremities is common and may last from days to months. Motor neuropathy usually affects the upper extremities more severely and may progress to quadriplegia, dysphagia and respiratory paralysis. Impairment of the autonomic nervous system may also occur and result in paralytic ileus. Tachycardia is frequently observed during an acute attack. Hyponatremia may be a complication and has been attributed to the syndrome of inappropriate secretion of antidiuretic hormone. ${ }^{16.17}$ Hypomagnesemia has also been reported and may be severe enough to cause tetany. ${ }^{17,18}$ Neuropsychiatric symptoms frequently observed include hysteria, depression, agitation, delirium, psychoses and seizures. ${ }^{14}$

\section{Pathology}

Postmortem studies on patients with acute intermittent porphyria indicate that pathologic changes may involve multiple areas in the central, peripheral and autonomic nervous systems. Both demyelination and axonal degeneration of peripheral and autonomic nerves have been reported in the literature. ${ }^{6,19,20}$ Ten Eyck and associates ${ }^{21}$ demonstrated patchy demyelination with extensive degeneration of neurons. Autopsy studies by Tschudy et a ${ }^{6}$ revealed large areas of chromatolysis, vacuolization and degeneration of neurons in the supraoptic nucleus of 
the hypothalamus. The mechanism of central nervous system involvement underlying the disease is not known. Several theories have been suggested to explain the chemical mechanism underlying an acute attack. It is possible that neurologic disturbances are caused by either a lack of heme in the nervous system or a toxic effect from excessive amounts of porphyrin precursors and their metabolites. Several investigators have demonstrated that delta-aminolevulinic acid and porphobilinogen, although not normally present in the cerebrospinal fluid, are detectable during acute episodes of porphyria. ${ }^{6,22,23}$ It is conceivable that certain changes occur in the blood-brain barrier during an attack, thereby allowing prophyrin precursors to gain entry into the central nervous system. It is also likely that because of higher plasma concentrations, porphyrin precursor concentrations in the cerebrospinal fluid become detectable without any change in the bloodbrain barrier.

\section{Precipitating Factors}

Acute intermittent porphyria may remain clinically latent for indefinite periods of time. The deficiency of the enzyme PBG deaminase does not necessarily lead to an attack, suggesting that superimposed factors come into play in precipitating an episode. Factors that are known to exacerbate AIP include a wide variety of chemicals and drugs, ${ }^{1,6.15,24-34}$ drastic changes in diet, ${ }^{31,35}$ starvation, bacterial and viral infections, certain endogenous hormones, onset of puberty, menstruation and pregnancy.

Drugs are frequently the cause of acute attacks of porphyria. Approximately $68 \%$ of the heme synthesized in the liver is used for the synthesis of cytochrome P-450, a microsomal enzyme that catalyzes mixed-function oxidations. ${ }^{2}$ Drugs and chemicals that are potent inducers of cytochrome P-450 are known to exacerbate AIP. An increase in the requirement for cytochrome P-450 leads to an increased demand for heme. This may partially deplete the regulatory heme pool and lead to induction of ALA synthase, so that the increased demand for heme can be met. It is not clear whether the induction of ALA synthase is mediated by increased synthesis of new enzyme or a stimulation of enzyme activity. Both methanisms may be operative, ${ }^{5}$ and it may also occur by other mechanisms. A drug or chemical may decrease the concentration of hepatic heme by either inhibiting the synthesis of heme or by accelerating its destruction. It is also possible that certain drugs may act directly on ALA synthase independent of changes in heme concentration. Drugs that induce cytochrome P-450 or ALA synthase or cause destruction of hepatic heme are best avoided if possible.

All barbiturates, whether alone or in combination with other drugs, are notorious for causing exacerbations of AIP and therefore must be avoided. ${ }^{15,24,26.27}$ Sulfonamides and their derivatives have been implicated in causing serious, even fatal, attacks of por- phyria ${ }^{26,27,30}$ Griseofulvin is a potent inducer of deltaaminolevulinic acid synthase and may induce an acute attack. ${ }^{27,30-32}$ The effect of many drugs on porphyria remains unknown. Drugs have been screened for their porphyrinogenic potential using either animal models or tissue cultures with chick embryo liver cell preparations. One must be cautious in extrapolating data from animals or tissue cultures to the clinical setting because of interspecies differences in metabolism. For example, rifampin is a potent enzyme inducer in man, although this effect is not seen in the rat. ${ }^{33 .}{ }^{34}$ Furthermore, patients with AIP respond differently to identical porphyrinogenic agents. Many agents do not consistently lead to an attack. For this reason all drugs should be carefully evaluated and merits weighed against risks with their use. Patients must be informed about the potential dangers of drugs and helped to recognize an impending attack. Tables 1 and 2 are a compilation of drugs reported to be safe or unsafe for use in acute intermittent porphyria. Table 3 includes drugs reported as both safe and unsafe, and over which there is still a great deal of controversy. The data have been extracted from reports in the worldwide literature, and references are cited should readers require more extensive information.

Drastic reduction in caloric intake is also known to precipitate acute clinical symptoms of porphyria. In a study by Welland and associates, ${ }^{35}$ a $60-80 \%$ reduction in daily intake in patients with AIP led to significant increases in urinary ALA and PBG excretion. Isocaloric substitution of fat for protein alone or for protein and carbohydrate had a similar effect. Addition of carbohydrate to the diet was associated with decreases in excretion of ALA and PBG. A reciprocal relationship was demonstrated between carbohydrate and/or protein intake and porphyrin precursor excretion in AIP. A specific link between sex hormones and the heme pathway at the enzyme level was first reported by Granick..$^{51}$ In chick embryo liver cell cultures it was demonstrated that estrone, estradiol, progesterone and testosterone stimulated excess porphyrin production. Further studies have revealed that many $C_{19}$ and $C_{21}$ steroids of the 5beta-hydroxy configuration can stimulate porphyrin synthesis. This was related to the induction of ALA synthase. ${ }^{52}$

\section{Management}

Prophylaxis is of utmost importance in preventing an attack of AIP. The patient must be informed about factors that may induce clinical symptoms. Severe reductions in caloric intake should be avoided. All drugs known to exacerbate the disease and all potent inducers of cytochrome P-450 should be avoided if possible.

In general, physicians should be extremely conservative in prescribing drugs for patients with acute porphyria. If a person with a known underlying genetic defect requires a drug that has not been tested, however, it is ethical to administer the agent cau- 
Table 1. Porphyrinogenic Drugs

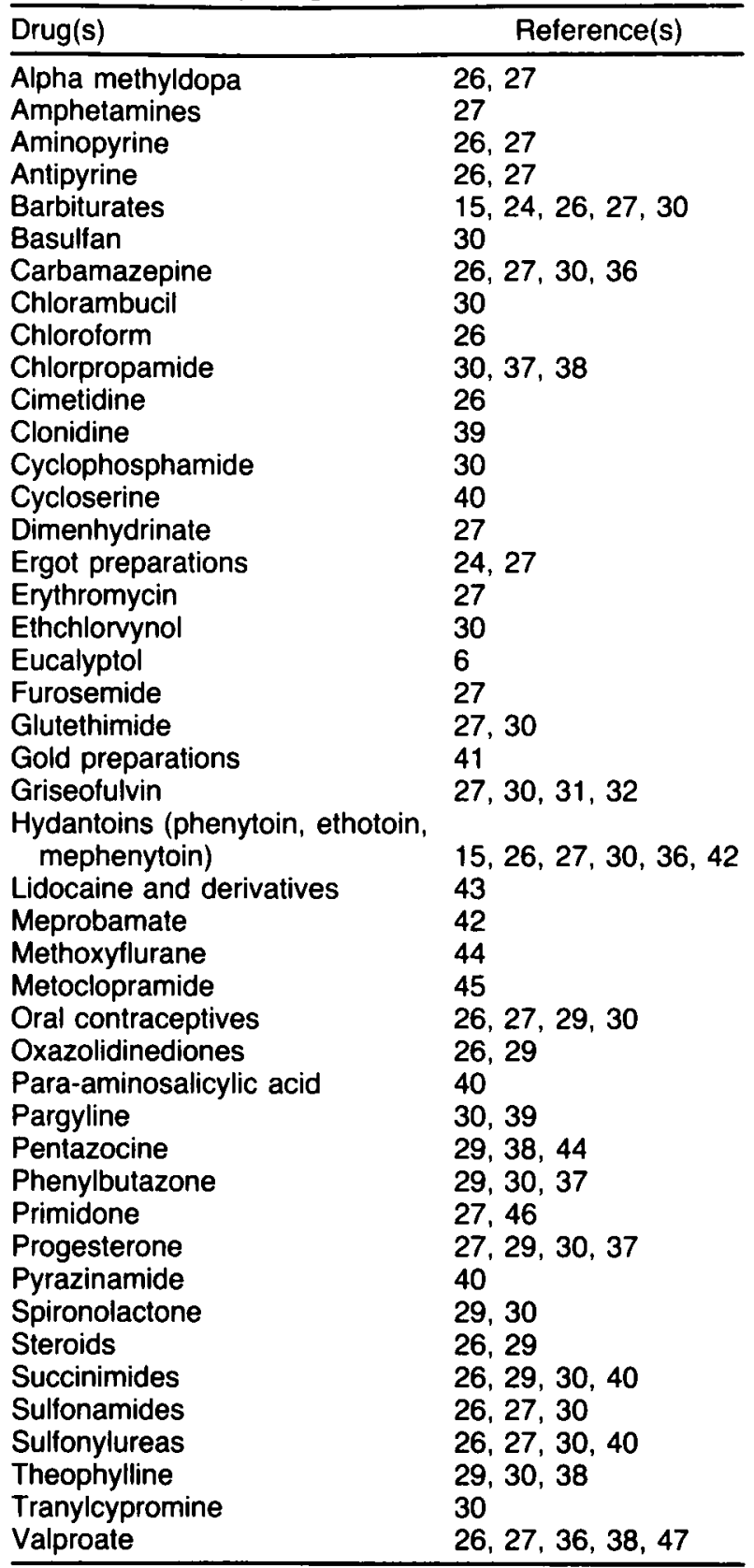

tiously and with close observation, including serial measurements of urinary excretion of ALA and PBG.

Another important feature is screening family members for detecting carriers of AIP, so that precautionary measures can be taken to prevent an attack. Evaluation should include quantitative determinations of urinary PBG and erythrocyte PBG deaminase. ${ }^{1,2,13}$

\section{Treatment of the Acute Attack}

Supportive care is necessary to control the acute
Table 2. Safe Drugs

\begin{tabular}{|c|c|}
\hline Drug(s) & Reference(s) \\
\hline Acetazolamide & 30 \\
\hline Adrenaline & 26 \\
\hline Aminoglycosides & 27 \\
\hline Aspirin & $26,27,29,30$ \\
\hline Bromides & 26,30 \\
\hline Beta blockers & $27,29,30$ \\
\hline Cephalosporins & 26,27 \\
\hline Chloral hydrate & $6,26,27,29,30$ \\
\hline Chlorpheniramine & 27,30 \\
\hline Chlorpromazine & $26,27,29,30$ \\
\hline Codeine & $24,26,27,30$ \\
\hline Colchicine & 26 \\
\hline Diazoxide & 30 \\
\hline Digitalis & $27,29,30$ \\
\hline Diphenhydramine & $6,27,30$ \\
\hline Dicumarol & 30 \\
\hline Droperidol & 29,30 \\
\hline Ethambutol & 40 \\
\hline Ether & $27,29,30$ \\
\hline Fentanyl & 43 \\
\hline Guanethidine & $26,27,29,30$ \\
\hline Heparin & 26 \\
\hline Ibuprofen & 26 \\
\hline Indomethacin & 26 \\
\hline Insulin & 26,30 \\
\hline Isoniazid & 40 \\
\hline Lithium & 26 \\
\hline Meperidine & 24 \\
\hline Methadone & 24 \\
\hline Methenamine mandelate & 27 \\
\hline Methylphenidate & 30 \\
\hline Morphine group & 24,43 \\
\hline Naproxen & 26 \\
\hline Neostigmine & $27,29,30$ \\
\hline Nitrous oxide & $27,29,30,44$ \\
\hline Nortriptyline & 27 \\
\hline Pancuronium & 43 \\
\hline Penicillins & $27,29,30$ \\
\hline Penicillamine & 26 \\
\hline Pethidine & 43 \\
\hline Prednisolone & 26 \\
\hline Primaquine & 27 \\
\hline Procaine and derivatives & $26,38,43,44$ \\
\hline Prochlorperazine & 27 \\
\hline Promethazine & $26,27,30,40$ \\
\hline Propantheline bromide & 26 \\
\hline Propoxyphene & $26,29,30,40$ \\
\hline Propranolol & $26,29,30$ \\
\hline Prostigmine & $26,27,30$ \\
\hline Quinine & 27 \\
\hline Reserpine & 27,30 \\
\hline Streptomycin & $6,27,30,40$ \\
\hline Succinylcholine & 29,30 \\
\hline Thiazides & 26,27 \\
\hline Thiouracil & 27 \\
\hline Thyroxine & 27 \\
\hline Trifluoperazine & 26,27 \\
\hline Tubocurarine & 26 \\
\hline Vitamins A-K & 27,30 \\
\hline
\end{tabular}


Table 3. Drugs Listed as both Safe and Unsafe

\begin{tabular}{ll}
\hline Drug(s) & \multicolumn{1}{c}{ Reference(s) } \\
\hline Amitryptiline & 26,27 \\
Androgens & 48 \\
Chloramphenicol & $26,29,30$ \\
Chlordiazepoxide & $26,27,29,30,42$ \\
Chloroquine & $26,27,29,37$ \\
Clonazepam & 36,47 \\
Diazepam & $26,29,30$ \\
Estrogens & $26,27,29,30,49$ \\
Ethanol & $26,27,29,30$ \\
Fentanyl & 29 \\
Halothane & 29,44 \\
Hydralazine & $26,30,39$ \\
Imipramine & $25,26,29,30,38,42$ \\
Ketamine & $26,27,29,30,44,50$ \\
Nitrofurantoin & 29,30 \\
Oxazepam & 26,29 \\
Paraldehyde & 26,30 \\
Pethidine & 29 \\
Probenecid & 26,30 \\
Progesterone & $26,27,29,30,49$ \\
Pyrimethamine & 26,27 \\
Rifampin & $29,30,33,34$ \\
Tetracycline & $6,26,27,29,30$ \\
\hline
\end{tabular}

symptoms and prevent complications. Hypertension and tachycardia can be adequately controlled with beta blockers. One patient who was suffering from severe hypertension and tachycardia during an attack was treated with propranolol. ${ }^{53} \mathrm{~A}$ total of dose of $284 \mathrm{mg}$ of propranolol was administered intravenously over a period of 18 hours. The acute symptoms subsided, and there was a concomitant decrease of porphyrin precursors in the urine. Administration of large doses of propranolol, however, is a dangerous practice and requires careful monitoring for hypotension and bradycardia. Bonkowsky and Tschudy ${ }^{54}$ reported a case in which two doses of propranolol $10 \mathrm{mg}$ administered intravenously six hours apart was followed by life-threatening hypotension and bradycardia. Menawat et al ${ }^{55}$ treated 20 patients during acute attacks with propranolol administered orally in dosages ranging from 20-200 $\mathrm{mg} /$ day. The hypertension and tachycardia were adequately controlled within 10 to 15 days of therapy.

Atenolol may be a suitable alternative to propranolol. To date, however, there are no published reports of its use in porphyria. Pain can be adequately controlled with codeine, meperidine or morphine if necessary. Chlorpromazine is a suitable antiemetic and in addition, serves to control the anxiety, neurosis and psychosis frequently observed during an attack. Promazine and trifluoperazine are also of value in management of psychosis. Choosing a drug is a problem when seizures complicate the picture be- cause anticonvulsants are known to exacerbate an attack. All anticonvulsant agents listed under the category of unsafe drugs are best avoided if possible. Numerous reports seem to indicate that bromide may be a useful alternative ${ }^{36,47.56}$ Careful monitoring of serum levels is necessary to avoid the many adverse toxic effects associated with bromide.

Carbohydrates are widely used in the treatment of acute attacks of AIP. Investigations on the effects of carbohydrates on porphyria followed the early findings that a high carbohydrate intake could prevent experimental porphyria. ${ }^{46}$ Welland and associates ${ }^{35}$ demonstrated that a high carbohydrate intake lowered urinary porphyrin precursors in AIP. Further studies revealed that carbohydrates could block the induction of certain enzymes, which was referred to as the glucose effect. ${ }^{28}$ Tschudy et $a{ }^{57}$ reported that in experimental animal models, large amounts of carbohydrates could prevent porphyria by blocking the induction of ALA synthase. Glucose feeding is known to repress activity of ALA synthase, although the mechanism for this repression has not been clarified. ${ }^{28}$ In a study by Giger and Meyer, ${ }^{58}$ an inhibitory effect of glucose on drug-mediated induction of ALA synthase was demonstrated in cultured hepatocytes. The glucose effect was dose-dependent and occurred in the complete absence of extrahepatic factors such as serum and hormones, implying a direct effect on hepatocytes and not necessarily mediated through hormonal or other metabolic changes. Glycerol ${ }^{59}$ is reported to be as effective as glucose in lowering porphyrin precursor excretion. During the acute attack, 300 to $500 \mathrm{~g}$ of glucose are administered per day, either orally or intravenously. Response is variable and may range from a dramatic recovery to no effect at all.

Hematin has been investigated in the treatment of attacks of AIP. ${ }^{60-67}$ Intravenous infusion has been found to be effective in reduction of the plasma as well as urinary concentrations of ALA and PBG. The effect has been more dramatic and clinical response to hematin has been more consistent than that seen with carbohydrates. In a number of trials, patients who were unresponsive to glucose responded to hematin. The optimum dose is not known. Dosages of 3-4 mg/kg body weight were selected somewhat arbitrarily and were found to be effective ${ }^{61,63.65} \mathrm{It}$ is not known whether smaller doses could also be effective clinically. Within 48 hours of administration, plasma concentration of porphyrin precursors decreased by $60-100 \%$ of prehematin values. Several days after the infusions were discontinued, the level gradually increased again to reach $50-100 \%$ of prehematin values, indicating that hematin-induced repression of ALA synthase was transient. Clinical response to the hematin varied with the severity of the attack. In many cases, patients refractory to glucose therapy showed a striking improvement clinically. ${ }^{61,63}$ As many as $20-50 \%$ of patients showed temporary improvement with relapse within 2 to 14 days. In 15$20 \%$ there was no apparent benefit from hematin. 
Hematin, an exogenous source of heme, is prepared as a lyophilized powder from hemin that is crystallized from human red cells, sterilized and made pyrogen free prior to administration. The solution is administered over 15 to 20 minutes through the tubing of a free-flowing saline infusion. Injections are given at 12- to 24-hour intervals for 3 to 5 days. Intravenously administered hematin is bound to albumin and hemopexin in the plasma. ${ }^{68.69}$ The mean concentration of circulating hemopexin, a beta-globulin, is only $77 \mathrm{mg} / 100 \mathrm{ml}^{70}$ When the hemopexin pool is saturated, hematin binds to albumin from where it is slowly released as free hemopexin becomes available. ${ }^{71,72}$ The heme-hemopexin complex is transferred to the liver where hematin is released and represses hepatic delta-aminolevulinic acid synthase ${ }^{63,72,73}$ The clearance of hematin from serum is biexponential, with a half-life for the first component ranging from 4.5 to 10.6 hours and for the second component 28 to 54 hours. ${ }^{63}$ Fifty percent to $70 \%$ of an administered dose is converted to bilirubin in the liver. ${ }^{74.75}$ Exogenously administered hematin ultimately appears in the bile as free hematin or bilirubin.

Few complications have been reported when hematin was administered in recommended doses. Dhar et $\mathrm{al}^{76}$ reported a case of transitory renal failure following rapid administration of $1,000 \mathrm{mg}$ in a patient with acute porphyria. The picture was consistent with acute tubular necrosis, which resolved after hematin was discontinued. It was theorized that this adverse effect resulted from significant amounts of circulating free hematin. Coagulopathy manifested by markedly prolonged prothrombin time, partial thromboplastin time and thrombocytopenia has been reported. ${ }^{77}$ Thrombophlebitis has been reported at the site of infusion. ${ }^{63}$

\section{Summary}

Acute intermittent porphyria is a hereditary disorder characterized by the deficiency of porphobilinogen deaminase, an enzyme necessary for the biosynthesis of heme. This results in over production, accumulation and excessive excretion of porphyrin precursors, notably delta-aminolevulinic acid and porphobilinogen. The disease is characterized by exacerbations and remissions. Many patients remain asymptomatic until a precipitating factor activates the disease to provoke an attack. Many drugs have been notorious in causing attacks.

During an acute attack the patient may experience abdominal pain, nausea, constipation, muscle weakness and neuropsychiatric symptoms. Treatment involves two therapeautic approaches: use of a highcarbohydrate diet and the administration of intravenous hematin.

One of the ultimate goals in acute intermittent porphyria is prevention of an attack by avoidance of known precipitating factors. It is important for clinicians to be familiar with drugs and other factors that have been known to cause acute attacks of por- phyria. The patient should be counseled and warned about potential danger of drugs so that acute, lifethreatening attacks of the disease can be prevented.

\section{References}

1. Kappas A, Sassa S, Anderson KE. The porphyrias. In: Stanbury JB Wyngaarden JB, Fredrickson DS, eds. The metabolic basis of inherited disease. New York: McGraw-Hill, 1983:1301-84.

2. Bonkowsky HL. Porphyrin and heme metabolism and the porphyrias. In: Zakin D and Boyer TD, eds. Hepatology: a textbook of liver disease. Philadelphia: WB Saunders, 1982:351-93.

3. Tait GH. The biosynthesis and degredation of heme. In: De Matteis F, Aldridge WN, eds. Heme and hemoproteins. Handbook of experimental pharmacology. New York: Springer-Verlag, 1978;44:1-48.

4. Granick S, Urata G. Increase in activity of delta-adminolevulinic acid synthetase in liver mitochondria induced by feeding of 3,5-dicarbethoxy-1,4-dihydrocollidine. J Biol Chem 1963;238:821-7.

5. De Mattels F. Hepatic porphyrias caused by 2-allyl-2-isopropylacetamide, 3,5-diethoxycarbonyl-1,4-dihydrocollidine, griseofulvin and related compounds. In: De Matteis F, Aldridge WN, eds. Heme and hemoproteins. Handbook of experimental pharmacology. New York: Springer-Verlag, 1978;44:129-55.

6. Tschudy DP, Valsamis M, Magnussen CR. Acute intermittent porphyria: clinical and selected research aspects. Ann Intern Med 1975; 83:851-64.

7. Battersby AR, Fookes CJR, Matcham GWJ, et al. Order of assembly of the four pyrrole rings during biosynthesis of the natural porphyrins. $J$ Chem Soc Chem Commun 1979;12:539-41.

8. Watson CJ, Taddeini L, Bossenmaier I. Present status of the Ehrlich aldehyde reaction for urinary porphobilinogen. JAMA 1964;190:501-4.

9. Mauzerall D, Granick S. Occurrence and determination of delta-aminolevulinic acid and porphobilinogen in urine. J Biol Chem 1956; 219:435-46.

10. Strand LJ, Meyer UA, Felsher BF, et al. Decreased red cell uroporphyrinogen I synthetase activity in intermittent acute porphyria. J Clin Invest 1972:51:2530-6.

11. Magnussen CR, Levine JB, Doherty JM, et al. A red cell enzyme method for the diagnosis of acute intermittent porphyria. Blood 1974; 44:857-68.

12. Bottomley SS, Bonkowsky HL, Kreimer-Birnbaum M. The diagnosis of acute intermittent porphyria. Usefulness and limitations of the erythrocyte uroporphyrinogen I synthase assay. Am J Clin Pathol 1981:76:133-9.

13. Mustajoki P. Normal erythrocyte uroporphyrinogen I synthase in a kindred with acute intermittent porphyria. Ann Intern Med 1981; 95:162-6.

14. Massey EW. Neuropsychiatric manifestations of porphyria. J Clin Psychiatry 1980;41:208-13.

15. Stein JA, Tschudy DP. Acute intermittent porphyria. A clinical and biochemical study of 46 patients. Medicine 1970;49:1-16.

16. Ludwig DG, Goldberg M. Hyponatremia in acute intermittent porphyria probably resulting from inappropriate secretion of antidiuretic hormone. Ann NY Acad Sci 1963;104:710-34.

17. Hellman ES, Tschudy DP, Bartter FC. Abnormal electolyte and water metabolism in acute intermittent porphyria: the transient inappropriate secretion of antidiuretic hormone. Am J Med 1962;32:734-46.

18. Nielsen B, Thorm MA. Transient excess urinary excretion of antidiuretic material in acute intermittent porphyria with hyponatremia and hypomagnesemia. Am J Med 1965;38:345-58.

19. Cavanagh JB, Mellick RS. On the nature of peripheral nerve lesions associaled with acute intermittent porphyria. J Neurol Neurosurg Psychiatry 1965;28:320-7.

20. Ridley A, Hierons R, Cavanagh JB. Tachycardia and the neuropathy of porphyria. Lancet 1968:2:708-10.

21. Ten Eyck FW, Martin WJ, Kernohan JW. Acute porphyria: necropsy studies in nine cases. Proc Mayo Clin 1961;36:409-22.

22. Sweeny VP, Pathak MS, Asbury AK. Acule intermittent porphyria: increased ALA-synthetase activity during an acute attack. Brain 1970; 93:369-80.

23. Bonkowsky HL, Tschudy DP, Collins A, et al. Repression of the overproduction of porphyrin precursors in acute intermittent porphyria by intravenous infusions of hematin. Proc Natl Acad Sci USA 1971; 68:2725-9.

24. Eales L. Acute porphyria: the precipitating and aggravating factors. S Afr J Lab Clin Med 1971:17:120-2. 
25. Disler PB, Blekkenhorat GH, Eales L, of al. Guidelines for drug prescription in patients with the acute porphyrias. S Afr Med J 1982;61:656-60.

26. Moore MR. International review of drugs in acule porphyria - 1980. Int J Biochem 1980;12:1089-97.

27. Eales L. Porphyria and the dangerous life-threatening drugs. S Afr Med J 1979;56:914-7.

28. Techudy DP. The influence of hormonal and nutritional factors on the regulation of liver heme biosynthesis. In: De Matteis F. Aldridge WN. eds. Heme and hemoproteins. Handbook of experimental pharmacology. New York: Springer-Verlag, 1978;44:255-71.

29. Wetterberg $L$. Report on an international survey of safe and unsale drugs in acute intermittent porphyria. In: Doss $M$, Nawrocki P, eds. Porphyrias in human diseases: report of the discussions. Freiburg: Falk, 1976;191-202.

30. Rifkind $\mathbf{A B}$. Drug-induced exacerbations of porphyria. Primary Care 1976;3:665-85

31. Felsher BF, Redeker AG. Acute intermittent porphyria: effect of diet and griseofulvin. Medicine 1967;46:217-23.

32. Berman A, Franklin RL. Precipitation of acute intermittent porphyria by griseofulvin therapy. JAMA 1965:192:1005-7.

33. Heubel T, Wetter KJ. Atypical inductive properties of rifampicin. Biochem Pharmacol 1979;28:3373-8

34. Ohnhaus EE, Park BK. Measurement of urinary 6-b-hydroxycortisol excretion as an in vivo parameter in the clinical assessment of the microsomal enzyme inducing capacity of antipyrine, phenobarbitone and rifampicin. Eur J Clin Pharmacol 1979;15:139-45.

35. Welland FH, Hellman ES, Gaddis EM, et al. Factors affecting the excretion of porphyrin percursors by patients with acute intermittent porphyria. I. The effect of diet. Metabolism 1964:13:232-50.

36. Reynolds NC, Miska RM. Safety of anticonvulsants in hepatic porphyrias. Neurology 1981;31:480-3.

37. Badamy AA. Treatment of acute hepatic porphyria (letter). Lancet 1978:1:1361-2.

38. Moore MA, McColl KE, Goldberg A. The porphyrias. Diabete Metab 1979:5:323-36.

39. Anderson KE. Effects of antihypertensive drugs on hepatic heme biosynthesis and evaluation of ferrochelatase inhibitors to simplify testing of drugs for heme pathway induction. Biochim Biophys Acta 1978:543:313-27.

40. Treece GL, Magnussen CR, Patterson JR, et al. Exacerbation of porphyria during treatment of pulmonary tuberculosis. Am Rev Respir Dis 1976:113:233-7.

41. Eisman JL, Alvares AP. Alterations induced in heme pathway enzymes and monooxygenases by gold. Mol Pharmacol 1978;14:117688.

42. Cowger ML, Labbe RF. Contraindications of biological-oxidation inhibitors in the treatment of porphyria. Lancet 1965;1:88-9.

43. De Verneull H, Deybach JC, Phung N, et al. Study of anaesthetic agents for their ability to elicit porphyrin biosynthesis in chick embryo liver. Biochem Pharmacol 1983;32:1011-8.

44. Parikh RK, Moore MR. Effect of certain anesthetic agents on the activity of rat hepatic delta-aminolevulinate synthase. Br J Anaesth. 1978;50:1099-108.

45. Doss M, Becker U, Kaffarmlk H. Drug safety in porphyria: risks of valproate and metoclopramide (letter). Lancet 1981:2:91.

46. Rose JA, Hellman ES, Tschudy DP. Effect of diet on the induction of experimental porphyria. Metabolism 1961:10:514-21.

47. Bonkowsky HL, Sinclair PR, Emery S, ot al. Seizure management in acute prophyria: risks of valproate and clonazepam. Neurology 1980; 30:588-93.

48. Lamon JM, Frykholm BC, Herrera W, ot al. Danazol administration to females with menses. Associated exacerbations of acute intermitten porphyria. J Clin Endocrinol Metab 1979;48:123-6.

49. Perlroth MG, Marver HS, Tschudy DP. Oral contraceptive agents and the management of acute intermittent porphyria. JAMA 1965:194: $1037-42$.

50. Rizk SF, Jacobson JH, Silva G. Kelamine as an induction agent for acute intermittent porphyria. Anaesthesiology 1977;46:305-6.
51. Granick $\mathbf{S}$. The induction in vitro of the synthesis of delta-aminolevulinic acid synthetase in chemical porphyria: a response to certain drugs, sex hormones and foreign chemicals. J Biol Chem 1966; 241:1359-75.

52. Kappas A, Song CS, Levere RD, ot al. The induction of delta-aminolevulinic acid synthetase in vivo in chick embryo liver by natural steriods. Proc Natl Acad Sci USA 1968;61:509-13.

53. Douer D, Wainberger A, Pinkhas J, et al. Treatment of acute intermittent porphyria with large doses of propranolol. JAMA 1978;240:766-8.

54. Bonkowrky HL, Tschudy DP. Hazard of propranolol in treatment of acute porphyria. Br Med J 1974:4:47-8.

55. Menawat AS, Panwar RB, Kockar DK, ot al. Propranolol in acute intermittent porphyria. Postgrad Med J 1979;55:546-7.

56. Magnussen R, Doherty JM, Hess RA, ot al. Grand mal seizures and acute intermittent porphyria. Neurology 1975;25:1121-5.

57. Techudy DP, Welland FH, Collins A, ot al. The effect of carbohydrate feeding on the induction of delta-aminolevulinic acid synthetase. Metabolism 1964:13:396-406.

58. Giger U, Meyer UA. Induction of delta-aminolevulinate synthase and cytochrome P-450 hemoproteins in hepatocyte culture. J Biol Chem 1981;256:1182-90.

59. Bonkowsky HL, Magnussen CR, Coilins AR, et al. Comparative effects of glycerol and dextrose on porphyrin precursor excretions in acute intermittent porphyria. Metabolism 1976;25:405-514.

60. Watson CJ, Dhar GJ, Bossenmaier I, et al. Effect of hematin in acute porphyric relapse. Ann Intern Med 1973;79:80-3.

61. McColl KEL, Moore MR, Thompson GG, et al. Treatment with hematin in acute hepatic porphyria. Q J Med 1981;198:161-74.

62. Peterson A, Bossenmaler I, Cardinal R, et al. Hematin therapy of acute porphyria: early remission of an almost fatal relapse. JAMA 1976;235:520-2.

63. Lamon JM, Frykholm BC, Hess RA, ef al. Hematin therapy for acute porphyria. Medicine 1979;58:252-69.

64. Dhar GJ, Bossenmaier I, Petryka ZJ, of al. Effects of hematin in hepatic porphyria: further studies. Ann Intern Med 1975;83:20-30.

65. Watson CJ, Plerach CA, Bossenmaier I, et al. Use of hematin in the acute attack of the "inducible" hepatic porphyrias. Adv Intern Med 1978:23:265-86.

66. McColl KEL, Moore MR, Thompson GT, et al. Hematin therapy and leucocyte delta-aminolevulinic acid synthase activity in prolonged attack of acute porphyria. Lancet 1979:1:133-4.

67. Bickers DA. Treatment of the porphyrias: mechanism of action. J Invest Dermatol 1981;77:107-13.

68. Muller-Eberhard U, Morgan WT. Porphyrin binding proteins in serum. Ann NY Acad Sci 1975;244:624-49.

69. Nyman M. On plasma proteins with heme or hemoglobin binding capacity. Scand J Clin Lab Invest 1960;12:121-30.

70. Hanstein A, Muller-Eberhard U. Concentration of serum hemopexin in healthy children and adults and in those with a variety of hematological disorders. J Lab Clin Med 1968;71:232-9.

71. Llem HH. Hepatic uptake of heme and hemopexin but not albumin. Biochem Biophys Acta 1974;343:546-50.

72. Muller-Eberhard U, Liem HH, Hanstein A, et al: Studies on the disposal of intravascular heme in the rabbit. J Lab Clin Med 1969; 73:210

73. Muller-Eberhard U. Hemopexin. N Engl J Med 1970;283:1090-4.

74. Snyder AL, Schmid R. The conversion of hematin to bile pigment in the rat. J Lab Clin Med 1965:65:817-24.

75. Pass IJ, Schwartz S, Wateon CJ. The conversion of hematin to bilirubin following intravenous administration in human subjects. J Clin Invest 1945;24:283-91

76. Dhar GJ, Bossenmaier I, Petryka ZJ. Transitory renal failure following rapid administration of a relatively large amount of hematin in a patient with acute intermittent porphyria in clinical remission. Acta Med Scand 1978;203:437-43.

77. Morris DL, Dudley MD, Pearson RD. Coagulopathy associated with hematin treatment for acute intermittent porphyria. Ann Intern Med 1981-95:700-1. 